\section{Coming closer to FDA reform}

The return of the US Congress from its summer recess may also bring reform to the Food and Drug Administration (FDA). The reform legislation was approved by a key Senate committee on June 18th, and awaits action by the full Senate. The House has similar legislation pending, but it has not progressed as far.

The bill (S 830) pitches the lawmakers and drug and medical device industries against consumer advocates.

The former seek to find ways to speed up the approval process for experimental drugs and devices. Senator James Jeffords (Republican, Vermont), who originally proposed the bill and is chairman of the Labor and Human Resources Committee, which recently passed the document, calls it "a moderate proposal" that will ensure "a strong FDA."

However, groups such as Public Citizen believe that hastening reviews will weaken the FDA and possibly hurt the public by allowing inadequately tested medicines and devices onto the marketplace. At a Public Citizen press conference, Arnold Relman, former editor of the New England Journal of Medicine, said, "This bill is not designed to improve the FDA. It's to castrate it, get it out of the regulatory business."

Similar legislation did not make it to the floor of either the House or the Senate last year, and as in 1996, the 1997 medical device review provisions have raised concerns. S 830 would allow experimental devices to be assessed by private experts hired by industry, which would pay for the privilege. The FDA would retain control over the process by certifying the reviewers in advance, and passing final judgment on the device following its recommendation.

But there is disagreement on whether this is the best way to manage approval of medical devices - which include everything from heart valves to bandages. While supporters insist this would hasten approval, opponents fear it will raise serious conflict-of-interest questions.

FDA officials have been evaluating a small pilot program that uses third-party reviewers, and believe such a program could work, although they oppose the idea of having such reviewers take charge of more complex medical devices, such as those that are implanted into the patient.

One controversial issue not in the original bill, but which will be brought to the fall debate by Senator Bill Frist (Republican, Tennessee), is the motion to allow drug companies to circulate peer-reviewed journal articles reporting the results of small studies of off-label drug use. Under current FDA statutes, manufacturers cannot distribute this type of information because it is regarded as illegal promotion. But many patient groups seek such access, arguing that physicians in rural areas or those not affiliated with large medical centers often are unaware of off-label uses.

FDA officials are nervous about the idea. "Doctors appropriately rely on journal articles all the time, but there are two problems associated with [relying on small studies]: companies lose the incentive to do the [larger] studies to get the answers and, occasionally,

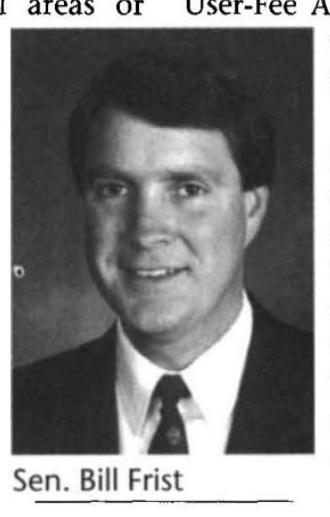
you'll have a medical disaster," says an agency official. Thus, the motion is likely to include a proviso that manufacturers agree to conduct the relevant studies to the FDA's satisfaction.

The recently revealed heart valve problems associated with the popular weight-loss drugs, fen-phen, is one example FDA officials cite. The drugs have never been approved by the FDA for use in combination and are licensed for single, short-term use only. But prescriptions increased 100-fold after a small study showed that the drugs worked islation.

better and had fewer side effects when used together.

In a change from last year, the current bill does not force the FDA to approve products already licensed outside the United States, and contains no provisions that would cause the agency to lose jurisdiction over products if it failed to meet tight review deadlines. It also relaxes restrictions on health claims that food companies can make. While the industry would still be required to gather scientific data to back claims, it would no longer need to undergo a cumbersome approval process. Instead, it would notify the FDA of the coming claim and the agency would have to act to stop it if it believed the claim to be false.

Finally, the bill's sponsors have deliberately included an action to reauthorize the highly popular Prescription Drug User-Fee Act (PDUFA) for a further five years, as an incentive for passing the rest of the bill.

Under the PDUFA, approved by Congress in 1992 and due to expire September 30 , companies must pay a fee to the FDA for each drug submitted for review. The money, which the Pharmaceutical Research and Manufacturers of America (PhRMA) association estimates to be around $\$ 106$ million if the bill is reauthorized, is used to hire additional drug reviewers.

Virtually everyone agrees that the program has accelerated the review process, but those unhappy with the other provisions of the bill would prefer that the PDUFA be acted upon separately. The FDA has announced that it has $\$ 24$ million set aside which could be used to pay federal salaries for up to six months if there is a delay in passing the PDUFA leg-

MARLene Cimmons Washington, D.C.

\title{
FDA revises drug broadcast rules
}

A ruling by the FDA that came into effect on August 8th could put an end to the obtuse advertisements for prescription medicines on American television and radio. Previously, consumers were left guessing as to which ailment a drug treated because marketers were permitted only to name the drug or to say which condition it treats, but not both unless labeling infor- mation was also presented. Hoechst Marion Roussel claims it will be the first company to take advantage of the new statute by revising its commercial for the hayfever drug Allegra. The old advertisement, depicting a man windsurfing across a field of wheat, tended to leave some audience members thinking that the drug was an aid to physical fitness.

K.B. 